\title{
Barriers and Facilitators to Event Greening Practices within the Corporate
}

\section{Barreiras e Facilitadores ao Greening em Eventos}

Miguel Moital

Professor in Events Management in the School of Tourism of Bournemouth University - BU, Bournemouth, United Kingdom

E-mail:mmoital@bournemouth.ac.uk

\section{Katherine Devenish}

Degree in Events Management by the Bournemouth University - BU, Bournemouth, United Kingdom

E-mail: miss_devenish@hotmail.co.uk 


\section{ABSTRACT}

This study explored the barriers and facilitators to event greening within the corporate sphere, attempting to reveal factors which expedite and impede event greening. A casestudy approach was utilised by interviewing six members of staff of a UK corporate event organisation. Although many barriers were present, potential facilitators were also uncovered. A lack of management support and formal policies as well as knowledge and resources acted as barriers to corporate event greening within the case-study organisation. Financial resources were also a facilitator, together with clients and temporal changes, therefore more barriers than facilitators were discovered. Many barriers were interconnected, appearing to stem from a short-term cost-benefit perspective. Recommendations for practice and for research are suggested.

Keywords: Barriers. Facilitators. Greening. Corporate Events. Business Events.

\section{RESUMO}

Este estudo explorou as barreiras e facilitadores do greening de eventos corporativos, revelando os fatores que aceleram e impedem o greening de eventos. Uma abordagem de estudo de caso foi utilizada ao entrevistar seis membros da equipe de uma organização de eventos corporativos do Reino Unido. Embora muitas barreiras estivessem presentes, facilitadores também foram descobertos. A falta de apoio gerencial e políticas formais, bem como conhecimento e recursos, atuaram como barreiras ao greening de eventos corporativos dentro da organização do estudo de caso. Os recursos financeiros também foram um facilitador, juntamente com clientes e mudanças temporais, e portanto, mais barreiras do que facilitadores foram descobertas. Muitas barreiras estão interligadas, parecendo ser consequência de uma perspectiva de custo-benefício de curto prazo. Recomendações para prática e pesquisa são sugeridas.

Palavras-chave: Barreiras. Facilitadores. Greening. Eventos Corporativos. Eventos de Negócios. 


\section{INTRODUCTION}

This research focuses on barriers and facilitators to greening within the corporate event industry. A barrier is anything which prevents, obstructs, or impedes while a facilitator is anything which assists, supports, or expedites. Event greening refers to the process of planning and running events in an environmentally friendly manner; reducing the resulting environmental impacts (Mair \& Jago, 2010). The realisation of the substantial potential negative environmental impacts of events has led to a drive towards greener practices. Event greening standards have become more apparent in recent years, evidenced in Britain by the development of BS:8901 in 2007, the first British Standard regarding event greening. Subsequently, an International Standard, ISO:20121, was created in 2012, illustrating the growing importance of, and interest in, green events.

Getz (2007) defines corporates events as any event produced for or by a corporation. This broad definition allows for the inclusion of the wide variety of corporate events, including conventions, meetings, conferences, award shows, and exhibitions. Corporate events account for the largest and fastest growing section of the event industry (O'Toole, 2011). The international corporate event market is worth $\$ 357.5$ billion each year; in the UK corporate events are worth nearly $£ 20$ billion annually to the economy, accounting for 57\% of all events held in 2011 (Mintel, 2012). Within corporate events, a drive for greening is often included within the environmental component of a Corporate Social Responsibility (CSR) policy (Jones, 2010). CSR policies often stipulate environmental requirements for suppliers (Dahlsrud, 2008) and within the corporate event industry, this may mean an organisation would hire an event organisation which had environmental policies in place. CSR policies are becoming increasingly prevalent (Ouwens, 2015), suggesting a shift towards more environmentally responsible operating. This increase in organisational environmental awareness is matched by event professionals who are increasingly interested in the environmental impacts of events (Laing \& Frost, 2010).

Despite the growing nature of the field, research into green issues is lacking within the events literature (Laing \& Frost, 2010). This study intends to add to the body of knowledge by exploring corporate events as other event genres, such as festivals, have received more attention (Jones, 2010). Research into the environmental impacts of festivals has shown more festivals to be implementing greening (Mair \& Laing, 2012). 
However the industry is a varied sector and the type of greening that is relevant for some event genres is not necessarily relevant to others (Dickson \& Arcodia, 2010).

Differentiated information attempting to discover environmental differences and similarities of non-homogenous event genres is needed (Dickson \& Arcodia, 2010).

Increasing emphasis is being placed on organisations to 'green' their events (Jones, 2010), therefore by exploring the barriers and facilitators to event greening as perceived by corporate event industry professionals, this paper makes contribution to the advancement of greener events.

\section{LITERATURE REVIEW}

\subsection{Approaches to studying barriers and facilitators to greening}

The study of barriers and facilitators to greening has been approached in several ways. Some authors focus on psychological aspects (Gifford, 2011), structural aspects (Stern, 1999), or demographic aspects (Liu, Vedlitz, \& Shi, 2014). Psychological aspects include knowledge, motivation, and social norms. Structural aspects include physical facilities such as transport. Demographic aspects include age, gender, and education. One psychological approach utilised in understanding green behaviour is goal theory. Unsworth, Dmitrieva, and Adriasola (2013) utilises goal-theory to explain why organisations may not undertake greening; focal goals, such as conserving finances, are central and the goal of greening is lower within the goal-hierarchy. Studies have employed a cost-benefit approach to understanding greening, assuming that individuals and organisations make reasoned choices, selecting options with the lowest cost and highest benefit (Steg \& Vlek, 2009). Costs and benefits can be psychological, such as the social approval associated with green behaviours, or structural factors, such as public transport links.

Prior to analysing barriers and facilitators to greening within organisations and events, barriers and facilitators to green behaviour within individuals will be assessed. Tudor, Barr, and Gilg (2008) shows those who undertake green behaviours at home are more likely to do so at work, highlighting the importance of assessing individual factors influencing greening. 


\subsection{Individual greening}

As noted in the introduction, individual factors affecting individual greening can be grouped into psychological, structural and demographic. With regards to psychological factors, research suggests that although most individuals exhibit at least some level of environmental concern, frequently this does not translate into behaviour (Kollmuss \& Agyeman, 2002). (Gifford, 2011, p. 290) posits psychological factors as the predominate reason for this discrepancy; developing a taxonomy of seven "dragons of inaction", which have been consolidated by Craddock, Huffman, and Henning (2012) into five 'dragons': limited cognition, ideology, social comparison, perceived risk and limited behaviour. Motivation can also influence individual greening. De Young (1996) argues that intrinsic motivation has a significant role in greening behaviours; a personal interest in greening leading to increased intrinsic motivation to undertake greening. Additionally, De Young (1996) states intrinsically motivated green behaviours provide satisfaction and this satisfaction facilitates future green behaviours. Extrinsic motivation (i.e. to pursue a reward) can also facilitate greening behaviours (Pelletier, GreenDemers, Tuson, Noels, \& Beaton,1998).

However, de Groot and Steg (2010) only found extrinsic motivation to be effective in motivating behaviours perceived to be simple and low-cost, such as recycling.

Although psychological factors undoubtedly influence individual greening, human behaviour is not solely driven by such factors. Many external structural factors also influence individual greening behaviours (Stern, 1999). Often, greening behaviours are only possible when necessary structural factors, such as recycling and public transport, are in place (Kollmuss \& Agyeman, 2002). When attempting to understand the differing levels of greening undertaken, many studies have focused on demographic characteristics such as age, gender, and education (e.g. e.g. Dietz, Stern, \& Guagnano, 1998; Liu et al., 2014).

\subsection{Organisational greening}

A review of the literature identified four factors influencing Organisational Greening (OG): Resources, management support, policy and knowledge. These can act as both a barriers and facilitators to OG.

Resources, including time, money, and physical resources, have been identified as factors which may influence OG. Several authors have illustrated that organisations 
perceive greening to be a costly undertaking, thus are unwilling to expend resources doing so (Revell \& Blackburn, 2007; Gaspar, 2013). However the desire for costreductions and profit increases, achieved through reducing physical resource usage and waste output, appear to act as a facilitator of OG (Studer, Welford, \& Hills, 2006; Dilchert \& Ones, 2012). Management support is frequently cited as an aspect which can influence OG. Lindgreen, Swaen, and Johnston (2009) states management support for OG corresponds with the level of greening an organisation undertakes. Reinforcing this, other authors have also view management support and commitment as essential in order for an organisation to undertake and maintain OG (Dilchert \& Ones, 2012; Zibarras \& Ballinger, 2012).

Environmental policies, one of the most common environmental initiative undertaken by organisations (Zibarras \& Ballinger, 2012), can facilitate OG when clearly stated (Harris \& Crane, 2002; Dilchert \& Ones, 2012) and communicated (Ramus \& Steger, 2000) as it provides guidelines and expectations which encourage employees to undertake the required behaviours (Ramus, 2002). However, Ramus and Steger's (2000) also showed the reverse to be true, the absence of a formal environmental policy was associated with employees undertaking fewer greening behaviours. It seems reasonable to posit that OG will not occur without knowledge of what greening measures can be taken and how to implement them. In other words, OG cannot occur without awareness-knowledge (knowing of its existence) and how-toknowledge (knowing how to do it) (Rogers, 2003). Lee (2009) states that SMEs are particularly disadvantaged in regards to environmental knowledge, often lacking resources to invest in innovations or training. This is a concern as training programmes have been shown to increase knowledge of environmental issues within managers and employees, and increase the amount of greening behaviours undertaken (Condon, 2004).

Although not identified as a common barrier to OG, Klewitz and Zeyen's (2010) findings that managers perceive greening as unwanted by customers is of interest as other research both supports and contradicts this. Revell and Blackburn (2007) found managers of SMEs perceived customers to be concerned with cost and quality, and blasé in regards to greening, therefore managers felt little impetus to be greener. Lee's (2009) findings, in contrast, found that increasing customer pressure is a significant driver for greening. However, in terms of corporate events greening, it may be that the desires of clients (the purchasing organisation) differ from customers (the event 
attendees). As stated in the introduction, organisations often have CSR policies which stipulate environmental requirements for suppliers (Dahlsrud, 2008), a different process to individual consumers expressing interest/disinterest in greening. Therefore, in the case of event greening, corporate event organisations may have to respond to their client's desires and conform to environmental requirements.

\subsection{Event greening}

The event greening literature is somewhat limited, with sporting mega-events and festivals dominating the discussion. Research into corporate events, often termed business events, is further limited. Existing research (Mair \& Jago, 2010; Merrilees \& Marles, 2011; Mair \& Laing, 2012) suggests events are influenced by many of the same factors influencing organisational greening. Form example, Mair and Jago (2010) state event-organisers perceive costs, and a lack of time and knowledge as significant barriers to event greening. However, an increase in clients with CSR policies has been found to be a significantly facilitating greening, due to the necessity of complying with these policies (Mair \& Jago, 2010). As events are often complex undertakings involving numerous sectors such as transport, catering, and accommodation, the degree to which all suppliers implement greening can pose a challenge to the overall greening of an event (Boo \& Park, 2013).

Event-organisers themselves also appear to facilitate event greening: if they hold strong green values they are more likely to seek out green options and implement event greening measures (Mair, 2014). This is particularly apparent within festivals where event greening is commonly a reflection of the organiser's personal values (Mair \& Laing, 2012). Merrilees and Marles (2011) state business events are more financially driven than other event genres and as such are influenced more by event greening financial concerns. Knowledge appears to be a factor influencing event greening. Boo and Park (2013) tested this argument through quantitative empirical research, finding knowledge of greening to positively influence green behaviour intentions. However, event-organisers were generally found to possess limited greening awareness (Boo and Park, 2013), therefore this lack of knowledge may pose a barrier to event greening. 


\section{METHODOLOGY}

\subsection{Research strategy}

As event greening is under researched, a qualitative study was designed in order to uncover the perceptions and experiences of Corporate Event Greening (CEG) that could lead to an understanding of barriers and facilitators. A case-study approach was selected for several reasons. First, case-studies have the ability to detect contextual issues better than wider-scope studies, providing powerful examples of particular phenomenon (Siggelkow, 2007). As this study focused on a specific phenomenon, a case-study allows the contextualisation of CEG within an organisations internal and external context. Second, Yin (2003) suggests a case-study is appropriate when understanding and exploring social phenomena is desired. Workplaces are inherently social, and social interaction in the workplace can influence organisational greening (Takeuchi, Yun, \& Wong, 2011). Third, Kohlbacher (2006) states that case-studies are of particular use when organisational and managerial processes are being studied. As seen from literature review, these types of processes have been found to be critical in influencing CEG.

\subsection{Data collection}

The case-study organisation was an SME operating from five regional UK offices, with headquarters outside London. The organisation produces and manages corporate events of all varieties, including award shows, conferences, and trade shows within the UK and Europe. Operating for over 25 years, the organisation is a key player within the UK corporate event industry. Additionally, unlike the majority of event organisations, they do not regularly outsource aspects of event design, production, or management. This 'in-house' approach allows the organisation a higher level of control over the whole process of staging a corporate event, therefore valuable in terms of exploring barriers and facilitators at every stage of event design and production.

The company had only a limited level of formalisation with regards to greening procedures, reflecting the little emphasis placed on greening. The only company document where the issue is addressed is the health \& safety manual which establishes a need to focus on controlling adverse effects on the environment and on complying with environmental laws. More specifically, the one page in the manual established that the company should endeavour to control and reduce the amount of packaging, control emissions to the atmosphere and liquid discharge, to minimise the amount of waste 
materials and of paper and similar products used, as well as to prevent the escape of waste from its business activities. Besides these generic objectives, no detail about how this should be achieved is provided. Therefore, the analysis is solely based on the data collected through interviews.

Semi-structured interviews with six members of staff within the selected organisation. The interview guide contained a number of pre-defined questions developed around eight themes: personal interest in greening, organisational culture, management, training, clients, company policy, resources and existing environmental demands. These themes were identified in the literature as key issues in facilitating/preventing greening. Permission to contact staff was obtained and participants were contacted directly. The interviews were undertaken in February 2015 outside the company premises, using various public spaces (e.g. cafés) to undertake the interviews. This was important to make staff feel secure and disclose any contentious issues/disagreements within the organisation with regards to greening practices. Hence the very basic description of the organisation and the participants. Interviews were scheduled to run for approximately 30 minutes, however they continued as long as the participant was continuing to provide valuable data (McGivern, 2008). The actual interview length varied between 25-38 minutes. Critical incident questions (Hughes, 2007) were used because asking participants about specific times when event greening previously occurred prompted them to reflect and explain experiences of event greening in the present.

Purposive sampling, common within interpretivist research (Onwuegbuzie \& Leech, 2007), was utilised in order to engage participants who could provide significant experiential accounts. Participants were sought from a variety of roles within the casestudy organisation: Two were event coordinators (Kelly and Louise), one was an event producer (Wayne), two were technical event crew (Tim and Dan) and one was the head of technical production (Mark). The objective of the research was to understand the company's standing with regards to greening and although small, the variety of participants in the sample was considered to be sufficient to achieve this aim. 


\subsection{Data analysis}

The adapted followed a mix of inductive and deductive thematic analysis. The inductive approach allowed grounded concepts and themes to emerge naturally, opposed to being solely constructed from prior assumptions or theories. The deductive component involved an exploration of the several key factors which can influence CEG identified in the literature. The coding process began with highlighting initial data sections, using colours to signify points of consonance (Braun \& Clarke, 2006). Next, the data began to be organised into groups and themes began to emerge. The coding guide was generated, specifying the colour ascribed to each code and grouping codes under broader themes where appropriate. The next stage involved re-evaluating the codes and themes, amending the coding guide to ensure it was as representative of the data as possible.

\section{RESULTS AND DISCUSSION}

\subsection{Greening undertaken}

In order to analyse barriers and facilitators to CEG within the case-study organisation, the greening measures that are in place were identified, providing an overview of the environmental nature of the organisation (Table 1).

As can be seen, a variety of practices are undertaken, or at least has procedures in place to undertake them. The practices are grouped according to the well-known 3R's of the waste hierarchy Hansen, Christopher, and Verbuecheln (2002). It can be seen the organisation has more recycling measures in place than reduction or reuse measures. This is in concurrence with Zibarras and Ballinger's (2012) findings that recycling is the most common organisational greening initiative. Zibarras and Ballinger (2012) outline several organisational greening methods commonly undertaken which the case-study organisation is not currently implementing, such as an environmental policy, energy efficient lighting, green energy purchasing and electronic filing. Therefore, it appears there is scope for the organisation to undertake more greening measures. 
Table 1 - Greening Undertaken by the Case-Study Organisation

\begin{tabular}{|l|l|l|}
\hline Recycling & Reusing & Reducing \\
\hline Fabric & Wood & Fuel \\
\hline Clothing & Set/stage pieces & Electricity \\
\hline Carpet & Scenery elements & \\
\hline Batteries & Foamex (foam signage boards) & \\
\hline Wood & & \\
\hline Delegate badges & & \\
\hline Branded items (e.g. pens) & & \\
\hline Paper & & \\
\hline
\end{tabular}

Source: Prepared by the author.

Taking the discovered procedures at face value assumes the organisation does indeed undertake these. However, participants expressed doubt as to whether several procedures, such as recycling paper, clothing, and batteries, are actually undertaken. Harris and Crane (2002) found similar gaps between espoused and actual positions in terms of organisational greening, suggesting that this is not specific to corporate events and is a more prevalent modus-operandi for varying organisations. This analysis aims to understand the barriers and facilitators to existing initiatives and other potential CEG measures which may not be in place.

\subsection{Management and organisational culture}

Management support and organisational culture were initially coded for separately within the data, however the analysis suggests the codes frequently link and the literature often discusses the two aspects in concurrently (Dilchert \& Ones, 2012).

Therefore they have been combined in order to fully assess their relevance in terms of ability to act as barriers and facilitators. An organisational culture which incorporates greening would encourage employees to hold shared green values and actively encourage green behaviour (Harris \& Crane, 2002). Participants expressed little awareness of any green culture within their organisation.

There isn't really a culture of being environmentally friendly, there really isn't, nobody's ever spoken to me... never about anything to do with it. It's certainly not something that people talk to me about or encourage me to pursue or even think about to be honest. (Wayne, Event Producer).

This leads to the supposition that the reverse of Harris and Crane's (2002) findings may also be valid: a lack of any green organisational culture may act as a barrier to CEG within the case-study organisation. Interestingly, Harris and Crane (2002) note that a green culture is challenging to achieve and suggest it might only be 
achieved via a concerted effort from the organisation's management. Dilchert and Ones (2012) link a strong environmental culture with an increased likelihood of environmental initiatives succeeding. Participants indicated that battery recycling containers had recently been introduced, however uncertainty was expressed in terms of them being utilised. This suggests the reverse of Dilchert and Ones (2012) findings may also be true; a weak environmental culture may decrease the likelihood of environmental initiatives succeeding. When asked what prevents the company from being greener, Tim (Technical event crew) said "Umm... being brutally honest... probably the attitudes of the management!".

When probed for clarification, Tim explained he felt management were apathetic in enforcing the existing event greening measures that were not seen as essential processes. Participants' views on what their management do perceive as essential processes suggest the organisations dominant philosophy is profit-based. Harris and Crane (2002) state that this is apparent for many organisations and that a profit-based philosophy often leads to the exclusion of environmental considerations, as in the casestudy organisation. Metcalf and Ben (2012) suggest that holistic organisational leadership takes into account the environmental aspects of business operations as well as economic drivers. In contrast to this, perceptual narrowing occurs as a result of leadership focus on the perceived most significant organisational facets and failure to recognise other aspects (Metcalf \& Ben, 2012). It appears perceptual narrowing and a profit-based philosophy may be pertinent within the case-study organisation, therefore constituting barriers to CEG.

Several participants perceived their management as unwilling to make changes in relation to greening due to the perceived favourability of current processes. For example, Dan (Technical event crew) said: "They think things are working the way they are so there's little reason to change anything.".

All but one participant shared the view that their management perceived greening in this manner. This suggests that the management are lacking the changeorientated behavioural dimension of leadership, which entails encouraging and accepting new ideas as part of a long-term perspective (Yukl, 1999). Interestingly, the outlying participant who perceived both an environmentally friendly culture and supportive management was the most senior, stating: 
that we have are aware and do what they can. (Mark, Head of technical production).

It has been argued that green values and actions espoused by management will be shared by less senior employees (Welford, 1995), yet this view is incongruent with the primary research findings as Mark's perception is not shared by other, less senior participants. This suggests that Harris and Crane's (2002) assessment that managers' ability to control organisational culture is optimistic at best is accurate in this instance.

The overall account of the culture and management support of the case-study organisation leads to the conclusion that these aspects act as significant barriers to CEG. Correspondingly, others (e.g. Zibarras \& Ballinger, 2012) have found that management support and commitment or the lack thereof is the most salient factor influencing organisational greening.

\subsection{Formal and informal policy}

Simultaneous coding highlighted that the majority of the greening measures described by participants in Table 1 took the form of informal policies. This study utilises Wharton, Chivers, and Blair-Loy's (2008) characterization of informal policies as those which are not written into official policy documents, but are operational within the organisation. The case-study organisation has a range of informal greening policies which are not formally stipulated as organisational rules. These policies rely on the selfregulated adherence of employees, which Tyler and Blader (2005) found to be effective in regulating employee behaviour. However, these informal polices were frequently not adhered to, therefore the existence of informal policies does not necessarily predict CEG within the case-study organisation. This may be due to the perceived apathy of the management as outlined earlier, resulting in employees' feeling little impetus to observe the informal policies.

Most participants concurred that there was not a formal environmental policy. When asked if they thought a formal policy should be in place, participants unanimously stated they felt one should be developed as it would encourage greening within the organisation. For example, Kelly (Event co-ordinator) said: "Yeah... definitely. Some kind of formal framework and definitely encouragement would probably mean people took notice of being a bit more environmentally friendly".

Their views are supported by Inoue and Alfaro-Barrantes' (2015) observation that formal environmental policies coupled with management support lead to higher 
levels of environmental measures undertaken. Additionally, Ramus and Steger's (2000) research demonstrated that the absence of a formal environmental policy was associated with employees undertaking fewer environmental initiatives. Therefore, a formal environmental policy may have the potential to facilitate CEG within the case-study organisation, and the lack of one may act as a barrier.

Dauber, Fink, and Yolles's (2012) model showing the links between two organisational artefacts, structure and behaviour, is applicable to CEG within the casestudy organisation. Structure, in this instance, is a formal environmental policy which stipulates rules and guidelines while behaviour refers to the employee behaviours which result from the structure. Dauber et al.'s (2012) model illustrates the link between organisational structures and the behaviours resulting from this, further reinforcing a formal environmental policy as a potentially significant facilitator of CEG within the case-study organisation.

\subsection{Resources}

Most participants indicated time and finance as resources they felt had an impact on the undertaking of event greening, both as a factor actively encouraging and one which prevented it. Participants specified that any measure of event greening which was viewed as resource conserving, that is, saving the organisation time or money, was actively encouraged by management and appeared to be complied with by employees: "We just started to recycle all our Foamex, which you know, is great from an environmental point of view but also from a financial point of view so everyone is trying to actually do that." (Kelly, Event Co-ordinator).

Linking back to the analysis in regards to management support, it is interesting to note that resource conserving green measures appeared to be those which employees act upon. This suggests the management are actively advocating greening measures which provide these types of economic benefits. Klewitz and Zeyen (2010) found economic benefits in terms of cost saving and time efficiency to be a significant driver to organisational greening. Hitchens, Clausen, Trainor, Keil, and Thankappan (2003) also notes that lower levels of resources and the desire for resource conservation is particularly operative within SMEs; such as the case-study organisation.

Participants indicated that finance impacted negatively on the undertaking of CEG, frequently making reference to the perceived cost-prohibiting nature of greening, suggesting finance is a significant barrier. "I'd say that cost is uh... if it had a cost at all, 
unless it's really very minimal it would probably be somewhat shunned." (Dan, Technical Event Crew).

Many authors agree that financial barriers to greening are prevalent, especially within SMEs due to lower cash flows and capital availability (Gerstenfeld \& Roberts, 2000; Hitchens et al., 2003). These financial barriers are inherent within smaller organisations, resulting in less greening undertaken as less capital reduces ability to invest in new initiatives, and due to the perceived expense of implementing new measures (Lee, 2009). This was affirmed by Mark (Head of technical production) stating: "More revenue means more money to invest in better gear and more greener technologies which we can't get now.".

The financial barrier may have been partially influenced by the 2008 recession which affected the event industry widely. The reduced number of corporate events and lower budgets resulting from the recession (Meeting Professionals International [MPI], 2009) led to changing industry trends. Notably, Hede (2007) reported in 2007 that environmental concerns were becoming more prominent within the event industry. However, post-recession Meeting Industry Association [MIA] (2009), an industry body, reported budget cuts and decreasing volumes of events as predominant concerns. Louise, an event co-ordinator, made specific mention to the recession in terms of its impact on levels of event greening:

At the moment with the recession and everything happening a few years ago then management are very concerned about budgets and trying to save as much money as possible still, they're still very much working on how it used to be... on a budget level.

This impact of the recession is supported by Studer et al. (2006) who stated that in time of financial compression, pressure to cut costs actively discourages greening within SMEs. Louise also stated that levels of event greening might only increase in conjunction with revenue, revealing a sense of finance acting as a facilitator. Other participants shared the view that any greening measure which was cost-saving was indeed implemented, even if not with green intentions.

We'd always have to keep you know, the vans down, so we're not just burning fuel up and down the motorway... but I guess that's probably to save on money and maybe not with particularly green intentions to be honest. (Kelly, Event Co-ordinator).

Operational cost-savings are a common organisational greening facilitator (Luetkenhorst, 2004), including within the case-study organisation as green measures which are perceived as commercially beneficial are implemented. Greening which 
results in operational cost-savings is often a short-term measure, as benefits from endeavours such as conserving fuel are realised immediately. This suggests that a shortterm financial perspective may pose a barrier to greening, as only those measures resulting in immediate financial gains are implemented. This perspective may result in measures which may have longer-term financial benefits not being implemented, due to the benefits being delayed opposed to immediate.

A shortage of available time and the need to allocate time for essential business processes, such as adhering to event schedules, was frequently mentioned by participants in terms of impacting upon both existing event greening measures and prospective measures: "When we're pushed for time and running from event to event to event in the busy season then sometimes the environmental procedures will go out the window." (Tim, Technical event crew).

This is in accordance with the literature on organisational greening. Gerstenfeld and Roberts (2000), Hitchens (2003), and Studer et al. (2006) found a perceived lack of time to be a critical factor in organisations not undertaking greening. This is particularly felt within SMEs as they more often characterised as time poor (Redmond, Walker, \& Wang, 2008). It could also be argued that the nature of the event industry, known for being fast-paced with frequently long hours (Wale, Robinson, \& Dickson, 2010), is a contributing factor to the lack of time available for greening felt by the participants. This is supported by Kelly statement when discussing the recycling of Foamex. "We're trying to enforce that properly because obviously at 4 o'clock in the morning, the crew... it's not going to be the first thing they think of if they're just ripping it down".

This suggests that a lack of time, or the pressure of time, acts as a barrier to existing greening measures within the case-study organisation. Several participants also stated that time posed a barrier to obtaining environmental certifications.

A lot of these accreditations and that you can get you know... credentials to
get have a lot of paperwork to be filled out, a lot of signatures to get um...
and time is a bit of a luxury to be honest. (Louise, Event Co-ordinator).

Perceiving time as a luxury and environmental accreditation as of less importance suggests that the case-study organisation operates with a short-term perspective. Formal accreditations require an environmental management system, the benefits of which are numerous and extensively reported, including cost savings, competitive advantage, and increased efficiency (Hillary, 2004). However organisations, particularly smaller firms, often view environmental management 
systems as providing uncertain future benefits, and as such are unwilling to make shortterm environmental commitments (Stoeckl, 2004). This short-term perspective may act as a barrier to CEG within the case-study organisation. Time as a barrier to greening was also mentioned in terms of the absence of the time needed to research greening measures, even though all participants expressed the wish to do so.

\subsection{Knowledge}

The literature suggests that insufficient knowledge is a significant barrier to organisational greening (Lee, 2009; Iraldo, Testa, \& Frey, 2010; Gaspar, 2013). Craddock et al., (2012) outlines limited cognition as a barrier to greening. Limited cognition appears to be present within the case-study organisation: although all participants had an awareness of greening, none were aware of the term 'event greening' as specifically applied to their industry. In line with Rogers's (2003) classification of types of knowledge, there was also a lack of awareness-knowledge, the first type of knowledge required to use an innovation, in this case CEG. "I don't really know about many green things like that and I'm not sure if other people do either. So yeah more knowledge might be good." (Dan, Technical event crew).

This infers insufficient knowledge as a barrier to CEG within the case-study organisation. However, as seen in Dan's statement above and other participants, knowledge of what CEG measures could be undertaken was frequently desired. This suggests if awareness-knowledge and subsequently how-to-knowledge (Rogers, 2003) was provided to participants, levels of CEG would increase, in line with Boo and Park's (2013) findings which revealed increased knowledge and levels of green behaviour intentions to be positively correlated. Therefore, knowledge appears to have the potential to also act as a facilitator to CEG.

However, training takes time and might incur financial costs. The evidence that the case-study organisation is unwilling or unable to allocate these resources to further greening might indicate an inability to train employees in greening matters. This suggests that a lack of training, and therefore a lack of knowledge, might act as a barrier to CEG. Additionally, it is interesting to note that when discussing a formal environmental policy, participants frequently expressed that one benefit of such a policy would be to increase awareness and knowledge in regards to event greening. As previously mentioned, participants all expressed support for a formal policy to be put in place, further highlighting the ability for knowledge to facilitate CEG. 


\subsection{Clients}

Participants strongly indicated client's desires as impacting the event greening undertaken by the organisation. Clients requested recycled materials to be used and new materials, such as wood for stage-sets, sourced from sustainable suppliers. Reusing event elements such as signage and stage-sets was also mentioned, as well as reducing the fuel and energy required to stage events. Therefore, client requests cover the 3R's of the waste hierarchy, outlined by Hansen et al. (2002). As Tim (Technical event crew) states:

One of our clients [name removed]... with them everything has to be green. It's all paperless, it's all uh, even down to the cups on site it's all recycled, and we have to use recycled materials as much as we can, but that's coming from their requests you know? I wouldn't say it's like that for every event unless a client does ask.

From this it appears that clients act a major facilitator to CEG. The literature revealed mixed views on end-users driving greening, but the findings of this study are in agreement with Iraldo et al. (2010) who state that requests and requirements of customers are a significant driving force for organisational greening, particularly in SMEs. Several participants expressed that client requests for, and interest in, CEG had increased in frequency over the last several years. When asked if this increased frequency was a noticeable trend, Mark (Head of technical production) responded: "Yes, yes definitely. That's something I've noticed, the questions about it... there's more of them and they are higher up the list you know?".

As organisations need to respond to changing trends within their markets (Pulendran, Speed, \& Widing, 2000), clients desires are a logical facilitator to CEG within the case-study organisation. However not all clients were reported to take an interest in CEG. There was variation in the levels that greening was requested and it tended to be clients from larger organisations who did so. This may link to CSR policies which often stipulate environmental requirements for suppliers (Dahlsrud, 2008), in this instance the case-study organisation. Therefore, clients appear to act as a facilitator.

This finding is in line with Mair and Jago's (2010) research into business events which found client's CSR policies to facilitate event greening. However, as typified in Tim's comment above, greening often stems directly from client requests. Therefore, clients without CSR policies or an interest in CEG may actually pose a barrier to CEG within the case-study organisation. 


\subsection{Temporal Changes}

Long-term and short-term temporal changes both within and externally to the case-study organisation were frequently mentioned as influencing CEG. This often linked with the changing desires of clients over the last several years, necessitating the case-study organisation to undertake more CEG in response. However, participants also expressed the necessity of keeping pace with the environmental developments of other event organisations as facilitating CEG. "I think more companies have those kinds of policies than before as well you know, more people are thinking about it as something they need to do". (Wayne, Event producer).

This may account for the increase in CEG processes stated by participants to be recently (within one year) incorporated into the organisations day-to-day operations. These included the introduction of battery recycling bins and recycling Foamex.

Therefore, the shift towards greener operating seen in the case-study organisation may be due to changing trends within other organisations, and the need to respond in accordance or be left behind, potentially resulting in the loss of clients or reputation (Pulendran et al., 2000). In regards to longer-term shifts towards CEG, Mark's account of temporal changes over his twenty two years of working in the industry shows that the passage of time has facilitated CEG:

\footnotetext{
There wasn't much direction at all when we first started out as to what the impact was of what we were doing... you know building an awful lot of things in wood and discarding things as one off items... once you did one event with it, it paid for itself from that event and became waste and was dumped... and it wasn't particularly recycled it just went off to the landfill you know? Now we modulate things so they're easily integrated into future events designs and recycle much more.
}

Mark outlines economic benefits as a reason for some of the changes towards greener operating, as modulating designs and reusing them ultimately conserves material costs. Operational cost-savings are a common facilitator to greening (Luetkenhorst, 2004) and the recognition over time of these benefits appears to have facilitated CEG within the case-study organisation.

This general shift to greener operating is not exclusive to the case-study organisation, or indeed the event industry as a whole. Environmental issues have become central to increasing numbers of organisations over the last few decades (Bartlett, 2011). In light of this and the participants' views, the passage of time appears to facilitate greening within the case-study organisation. 


\section{CONCLUSIONS AND RECOMMENDATIONS}

This study sought to explore the barriers and facilitations to event greening in the corporate sector. Focusing on a UK corporate event organiser, the multiple barriers and facilitators to corporate event greening (CEG) were explored and contextualised in relation to applicable literature.

The findings revealed a lack of management support and formal policies, green culture, knowledge, and the resources of finance and time as the predominant barriers. Financial resources were also a facilitator, together with clients and temporal changes, therefore more barriers than facilitators were discovered. The most significant barrier is the lack of management support, appearing to directly impact employees undertaking the organisations informal CEG policies. Zibarras and Ballinger (2012) stated that higher levels of greening are undertaken when management are supportive towards organisational greening. This finding indicated that the reverse may also be accurate; apathetic management results in lower levels of greening.

The interconnectedness of many of the barriers and facilitators came to light within the analysis. Management apathy towards CEG appears to contribute towards the lack of green organisational culture and participants feeling little impetus to be green. This is in line with Epstein, Buhovac, and Yuthas (2010) findings that leadership plays an integral part in encouraging a green organisational culture. Time as a resource and knowledge were also connected. Most participants desired more CEG knowledge, but frequently felt they had no time to research and improve their understanding. This may be indicative of the fast pace of the events industry (Wale et al., 2010) coupled with the time poor nature of SMEs generally (Redmond et al., 2008).

Employees' desire for a formal environmental policy providing a CEG framework and guidelines, suggests if managerial support was given, employees would implement the CEG measures. Employees are a vital component of organisational greening, often directly implementing greening strategies and measures (Tinnish \& Mangal, 2012). Participants expressed that not all the current CEG measures within the case-study organisation were being adhered to. This noncompliance coupled with the desire for a formal policy and guidelines suggests that participants do not want to selfregulate their greening behaviour, instead preferring official stipulations. This is opposed to Tyler and Blader (2005) who found self-regulation was more effective in controlling employee behaviour than formal guidelines. 
Participants perceived financial issues as a significant barrier and facilitator to CEG within the case-study organisation. Greening which provided immediate or shortterm benefits, such as reducing fuel use which in turn conserves finances, was implemented and actively supported by management. Conversely, measures seen as requiring resource expenditure for perceived uncertain future benefits, such as environmental accreditation, were not supported. This indicates a short-term costbenefit organisational perspective, where immediate profit is prioritised over future, potentially higher profits, as the economic benefits of organisational greening are well documented (Dixon-Fowler, Slater, Johnson, Ellstrand, \& Romi, 2013). A short-term, profit-centric business philosophy has also been documented by Harris and Crane (2002) as affecting organisational greening.

An explanation for why the management appear unsupportive of CEG, therefore unwilling to expend resources undertaking it, may stem from goal-theory. Unsworth et al. (2013) states resource conservation is a focal organisational goal, thus any drive for greening is often lower within the goal-hierarchy. Within this view, managers may perceive that undertaking greening detract resources thus negatively impacting on their focal goals.

The temporal changes described by participants are encouraging as they indicate that despite the barriers to CEG, as outlined above, the case-study organisation has been moving in a greener direction over time. Although various barriers are present, there also appears to be potential for many facilitating factors to become operational within the organisation. As the number of organisations with CSR policies is increasing (Ouwens, 2015), this means increasing numbers of the case-study organisation's clients are likely to be placing emphasis on greening their events (Jones, 2010). Therefore, event suppliers, such as the case-study organisation and other corporate event SMEs, are likely to be required to implement higher levels of CEG in the future. In light of this, several recommendations are presented below.

\subsection{Recommendations for practice and future research}

Several aspects of this study may prove of use to the managers of corporate event organisations. However, as a significant barrier to CEG greening was found to be a lack of management support, these recommendations will be of use to only those managers who do desire to undertake/increase CEG. This study has several important implications for practice. First, a formal environmental policy with clear stipulations 
and guidelines was found to be a significant facilitator. Therefore, a formal environmental policy would encourage a greening culture, thus increasing corporate event greening. Second, focusing on short term benefits only means that longer-term benefits of corporate event greening are not considered. From a resource perspective, a long-term view may enable better resource utilisation and conservation, as well as higher levels of organisational greening. Third, increasing knowledge is linked to increased levels of greening and if formal training is not possible due to resource constraints, informal dissemination of knowledge from management down should take place. Employees should be actively encouraged to seek out and research greening measures. Free resources and guidelines, such as The Carbon Trust and Green Business, a free government organisational greening resource, can be utilised without financial expenditure. Finally, operational cost-savings were found to be a significant facilitator. Managers are therefore recommended to increase their knowledge in order to fully understand the potential benefits of corporate events.

Several avenues for future research have been identified in the hope that this study provides a base-point for subsequent inquiries into this under-researched area. The exploratory nature of this study opens up several areas for future research. First, the organisation focus of this study was a low level adopter of greening behaviours. Future research could focus on higher level adopters, for example those that position themselves according to greening credentials. Second, future research could concentrate its efforts on case-studies of international corporate event organisations. Findings from several countries would provide more in-depth, generalisable data, with information regarding any cultural differences towards corporate event greening revealed. Third, exploring common and discrepant barriers and facilitators to CEG across different corporate event organisations would broaden the information about the state of the industry as a whole. Finally, ascertaining the degree to which the clients of corporate event organisations perceived barriers and facilitators to corporate event greening could also be pursued. This would provide a new perspective on the research topic, further enriching this under-studied area. In light of the increasing importance of the environmental impacts of events (Getz, 2012), further research with clear, practical guidelines for practitioners is likely to continue to be necessary for the foreseeable future. 


\section{REFERENCES}

Bartlett, D. (2011). Introduction. In: Bartlett D. (Ed.). Going green: the psychology of sustainability in the workplace. Leicester: The British Psychological Society, 47-58.

Boo, S., \& Park, E. (2013). An examination of green intention: the effect of environmental knowledge and educational experiences on meeting planners' implementation of green meeting practices. Sustainable tourism, 21(8), 1129-1147.

Braun, V., \& Clarke, V. (2006). Using thematic analysis in psychology. Qualitative research in psychology, 3(2), 77-101.

Condon, L. (2004). Sustainability and small to medium sized enterprises: how to engage them. Australian journal of environmental education, 20(1), 57-67.

Craddock, E., Huffman, A., \& Henning, J. (2012). Taming the dragon: how industrialorganizational psychologists can break barriers to 'green' business. Industrial and organizational psychology, 5(4), 484-487.

Dahlsrud, A. (2008). How corporate social responsibility is defined: an analysis of 37 definitions. Corporate social responsibility and environmental management, 15(1), 113.

Dauber, D., Fink, G., \& Yolles, M. (2012). A Configuration Model of Organizational Culture. SAGE Open, 1-16.

De Young, R. (1996). Some psychological aspects of reduced consumption behaviour: the role of intrinsic motivation and competence motivation. Environment and behaviour, 28(3), 358-409.

Dickson, C., \& Arcodia, C. (2010). Promoting sustainable event practice: the role of professional associations. Hospitality management, 29(2), 236-244.

Dietz, T., Stern, P. C., \& Guagnano, G. A. (1998). Social structural and social psychological bases of environmental concern. Environment and behaviour, 30(4), 450471.

Dilchert, S., \& Ones, D. (2012). Environmental sustainability in and of organizations. Industrial and organizational psychology, 5(4), 503-511.

Dixon-Fowler, H., Slater, D., Johnson, J., Ellstrand, A., \& Romi, A. (2013). Beyond 'does it pay to be green?' A meta-analysis of moderators of the CEP-CFP relationship. Business ethics, 112(2), 353-366.

Epstein, M., Buhovac, A., \& Yuthas, K. (2010). Implementing sustainability: the role of leadership and organizational culture. Strategic finance, 91(10), 41-47.

Gaspar, R. (2013). Understanding the reasons for behavioural failure: a process view of psychosocial barriers and constraints to pro-ecological behaviour. Sustainability, 5(7), 2960-2975.

Gerstenfeld, A., \& Roberts, H. (2000). Size matters: barriers and prospects for environmental management in small and medium-sized enterprises. In: Hillary, R. (Ed.). Small and medium-sized enterprises and the environment. Sheffield: Greenleaf, 106118.

Getz, D. (2007). Event studies: theory, research and policy for planned events. Oxford: Elsevier 
Getz, D. (2012). Event studies: discourses and future directions. Event management, 16(2), 171-187.

Gifford, R. (2011). The dragons of inaction: psychological barriers that limit climate change mitigation and adaptation. American psychologist, 66(4), 290-302.

Groot, J. I. M., \& Steg, L. (2010). Relationships between value orientations, selfdetermined motivational types and pro-environmental behavioural intentions. Environmental psychology, 30(4), 368-378.

Hansen, W., Christopher, M., \& Verbuecheln, M. (2002). EU waste policy and challenges for regional and local authorities. Berlin: Institute for International and European Environmental Policy.

Harris, L., \& Crane, A. (2002). The greening of organizational culture. Organizational change management, 15(3), 214-234.

Hede, A. (2007). Managing special events in the new era of the triple bottom line. Event management, 11(1/2), 13-22.

Hillary, R. (2004). Environmental management systems and the smaller enterprise. Cleaner production, 12(6), 561-569.

Hitchens, D., Clausen, J., Trainor, M., Keil, M., \& Thankappan, S. (2003).

Competitiveness, environmental performance and management of SMEs. Greener management international, 44(3), 45-57.

Hughes, H. (2007). Critical incident technique. In: Lipu, S., Williamson, K., \& Lloyd, A. (Eds.). Exploring methods in information literacy research. New South Wales: Charles Stuart University, pp. 49-66.

Inoue, Y., \& Alfaro-Barrantes, P. (2015). Pro-environmental behaviour in the workplace: a review of empirical studies and directions for future research. Business and society, 120(1), 137-160.

Iraldo, F., Testa, F., \& Frey, M. (2010). Environmental management system and SMEs: EU experience, barriers and perspectives. In: Sarkar, S. (Ed.). Environmental management. Croatia: Sciyo, 1-34.

Jones, M. (2010). Sustainable event management. London, UK: Earthscan.

Klewitz, J., \& Zeyen, A. (2010). The role of intermediary organizations in ecoefficiency improvements in SMEs. Lüneburg: Centre for Sustainability Management.

Kohlbacher, F. (2006). The use of qualitative content analysis in case study research. Qualitative social research, 7(1), 1-23.

Kollmuss, A., \& Agyeman, J. (2002). Mind the gap: why do people act environmentally and what are the barriers to pro-environmental behaviour?. Environmental education research, 8(3), 239-260.

Laing, J., \& Frost, W. (2010). How green was my festival: exploring challenges and opportunities associated with staging green events. Hospitality management, 29(2), 261267.

Lee, K. (2009). Why and how to adopt green management into business organizations: The case study of Korean SMEs in manufacturing industry. Management decision, 47(7), 1101-1121. 
Lindgreen, A., Swaen, V., \& Johnston, W. (2009). Corporate social responsibility: an empirical investigation of US organizations. Business ethics, 85(2), 303-323.

Liu, X., Vedlitz, A., \& Shi, L. (2014). Examining the determinants of public environmental concern: evidence from national public surveys. Environmental science and policy, 39(5), 77-94.

Luetkenhorst, W. (2004). Corporate social responsibility and the development agenda. Intereconomics, 39(3), 157-166.

Mair, J., \& Jago, L. (2010). The development of a conceptual model of greening in the business events tourism sector. Sustainable tourism, 18(1), 77-94.

Mair, J., \& Laing, J. (2012). The greening of music festivals: motivations, barriers and outcomes: applying the Mair and Jago model. Sustainable tourism, 20(5), 683-700.

Mair, J. (2014). Greening events. In: DeLacy, T., Jiang, M., Lipman, G., \& Vorster S. (Eds.). Green Growth and travelism: concept, policy and practice for sustainable tourism. Oxford: Abingdon.

McGivern, Y. (2008). The practice of market research. (3rd ed.). Essex: Pearson Education.

Meeting Industry Association (MIA). (2009). Actual impact of the 'credit crunch' on the conference and events market. London: Meeting Industry Association.

Meeting Professionals International (MPI). (2009). Business barometer. Dallas: Meeting Professionals International.

Merrilees, B., \& Marles, K. (2011). Green business events: profiling through a case study. Event management, 15(4), 361-372.

Metcalf, L., \& Benn, S. (2012). The corporation is ailing social technology: creating a 'fit for purpose' design for sustainability. Business ethics, 111(2), 195-210.

Mintel. (2012). The European MICE industry. London: Mintel Group.

Onwuegbuzie, A., \& Leech, N. (2007). Sampling designs in qualitative research: making the sampling process more public. Qualitative report, 12(2), 238-254.

O'Toole, W. (2011). Events feasibility and development: from strategy to operations. London: Butterworth-Heinemann.

Ouwens, F. (2015). The role of imagineering as an event design strategy in the business event industry. In: Richards, G., Marques, L., \& Mein, K. (Eds.). Event design: social perspectives and practices. Abingdon: Routledge.

Pelletier, L., Green-Demers, I., Tuson, K., Noels, K., \& Beaton, A. (1998). Why are you doing things for the environment? The motivation toward the environment scale.

Applied social psychology, 28(5), 437-468.

Pulendran, S., Speed, R., \& Widing, R. (2000). The antecedents and consequences of market orientation in Australia. Australian journal of management, 25(2), 119-144.

Ramus, C. A. (2002). Encouraging innovative environmental actions: what companies and managers must do. World business, 37(2), 151-16.

Ramus, C. A., \& Steger, U. (2000). The roles of supervisory support behaviours and environmental policy in employee eco-initiatives at leading-edge European companies. Academy of management, 43(4), 605-626. 
Redmond, J., Walker E., \& Wang, C. (2008). Issues for small businesses with waste management. Environmental management, 88(2), 275-285.

Revell, A., \& Blackburn, R. (2007). The business case for sustainability? An examination of small firms in the UK's construction and restaurant sectors. Business strategy and the environment, 16(6), 404-420.

Rogers, E. M. (2003). Diffusion of innovations. (5th ed.). London: Simon and Schuster. Siggelkow, N. (2007). Persuasion with case studies. Academy of management, 50(1), 20-24.

Steg, L., \& Vlek, C. (2009). Encouraging pro-environmental behaviour: an integrative review and research agenda. Environmental psychology, 29(3), 309-317.

Stern, P. C. (1999). Information, incentives, and pro-environmental consumer behaviour. Consumer policy, 22(4), 461-478.

Stoeckl, N. (2004). The private costs and benefits of environmental self-regulation: which firms have most to gain?. Business strategy and the environment, 13(3), 135-155.

Studer, S., Welford, R., \& Hills, P. (2006). Engaging Hong Kong businesses in environmental change: drivers and barriers. Business strategy and the environment, 15(6), 416-431.

Takeuchi, R., Yun, S., \& Wong, K. (2011). Social influence of a co-worker: a test of the effect of employee and co-worker exchange ideologies on employees' exchange qualities. Organizational behaviour and human decision processes, 115(2), 226-237.

Tinnish, S. M., \& Mangal, S. M. (2012). Sustainable event marketing in the MICE industry: a theoretical framework. Convention and event tourism, 13(4), 227-249.

Tudor, T., Barr, S., \& Gilg, A. (2008). A novel conceptual framework for examining environmental behaviour in large organizations: a case study of the Cornwall National Health Service (NHS) in the United Kingdom. Environment and behaviour, 40(3), 426450 .

Tyler, T., \& Blader, S. (2005). Can businesses effectively regulate employee conduct? The antecedents of rule following in work settings. Academy of management journal, 48(6), 1143-1158.

Unsworth, K., Dmitrieva, A., \& Adriasola, E. (2013). Changing behaviour: increasing the effectiveness of workplace interventions in creating pro-environmental behaviour change. Organizational behaviour, 34(2), 211-229.

Wale, D., Robinson, P., \& Dickson, G. (2010). Events management. Oxfordshire, CABI.

Welford, R. (1995). Environmental strategy and sustainable development. London: Routledge.

Wharton, A., Chivers, S., \& Blair-Loy, M. (2008). Use of formal and informal workfamily policies on the digital assembly line. Work and occupations, 35(3), 327-350.

Yin, R. (2003). Case study research: design and methods. (3rd ed.). London: Sage.

Yukl, G. (1999). An evaluative essay on current conceptions of effective leadership.

European journal of work and organizational psychology, 8(1), 33-48. 
Zibarras, L., \& Ballinger, C. (2012). Promoting environmental behaviour in the workplace: A survey of UK organisations. In: Bartlett, D. Going green: The psychology of sustainability in the workplace. (Chap. 10, pp. 84-90). London: The British Psychological Society.

FORMAT FOR QUOTATION OF THIS ARTICLE

RODRIGUES, L. M. M., \& DEVENISH, K. (2019). Barriers and Facilitators to Event Greening Practices within the Corporate. Revista de Turismo Contemporâneo, 7(1), 127. https://doi.org/10.21680/2357-8211.2019v7n1ID16519 